Jan-Henning Wyen

\title{
Rechtswahlfreiheit im europäischen Insolvenzrecht
}

Eine Untersuchung zum forum shopping unter der EuInsVO unter besonderer Berücksichtigung von Effizienzgesichtspunkten

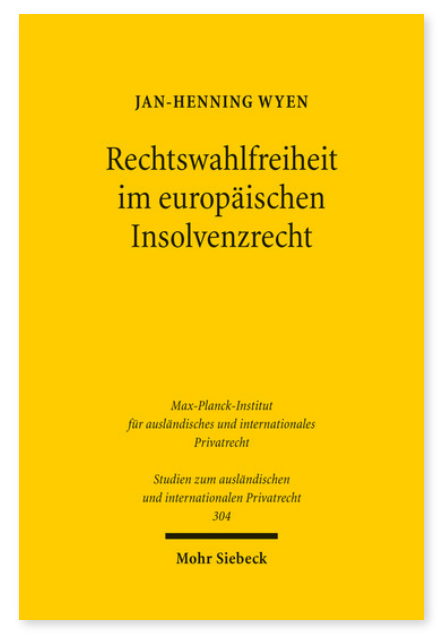

2014. XXX, 400 Seiten. StudIPR 304

ISBN 978-3-16-152313-7

DOI 10.1628/978-3-16-152313-7

eBook PDF 94,00€

ISBN 978-3-16-152246-8

fadengeheftete Broschur 94,00€
Eine zentrale Weichenstellung der Zuständigkeitsermittlung gemäß der Europäischen Insolvenzverordnung wird durch den 'Mittelpunkt der hauptsächlichen Interessen', einen unbestimmten Rechtsbegriff, beherrscht. Den Verfahrensbeteiligten wird hierdurch in begrenztem Umfang die Möglichkeit vermittelt, Einfluss auf den Verfahrensort und damit auf das im Insolvenzverfahren zur Anwendung kommende mitgliedstaatliche Insolvenzrecht zu nehmen. Jan-Henning Wyen untersucht die im Spannungsfeld von Zuständigkeits- und Anerkennungsregeln entstehenden Einwirkungsmöglichkeiten der Verfahrensbeteiligten, die er als faktische Rechtswahlfreiheit begreift, und ihre gegenständliche Reichweite unter Berücksichtigung des deutschen Insolvenz- und Gesellschaftsrechts. Darüber hinaus analysiert er das Einflussnahmepotential und die damit verbundenen Anreizstrukturen unter Effizienzgesichtspunkten. Im Spiegel der gewonnenen Erkenntnisse setzt er sich abschließend mit den Vor- und Nachteilen alternativer Regelungsmodelle auseinander.

Jan-Henning Wyen Geboren 1979; Studium der Rechtswissenschaften in Heidelberg, Lausanne, Münster und München; Referendariat am Landgericht Düsseldorf; 2009 LL.M. (Columbia); seit 2009 Rechtsanwalt in München; 2012 Promotion.

Jetzt bestellen:

https://mohrsiebeck.com/buch/rechtswahlfreiheit-im-europaeischen-insolvenzrecht-9783161523137?no_cache=1 order@mohrsiebeck.com

Telefon: $+49(0) 7071-923-17$

Telefax: $+49(0) 7071-51104$ 